\title{
LETRAMENTO ACADÊMICO DE ALUNOS DE LETRAS: CONSTRUINDO POSSIBILIDADES DE ATITUDES ATIVAS E TÁTICAS
}

Lúcia de Fátima Santos (Universidade Federal de Alagoas)

RESUMO

Este artigo resulta de uma pesquisa de cunho etnográfico, desenvolvida na área de Linguística Aplicada, com o objetivo de compreender a constituição de alunos de Letras como produtores de textos escritos em português, visando a atitudes ativas e táticas. 0 corpus é formado por entrevista e atividades de escrita e reescrita de textos dos mesmos alunos, realizadas no decorrer de duas disciplinas do curso de Letras, ministradas pela mesma professora. A análise dos dados indica poucos momentos em que os alunos apresentam atitudes ativas e táticas no processo de escrita, nas atividades realizadas nas duas disciplinas. Esse resultado se atribui, entre outras razões, à história de cada aluno como produtor de textos na educação básica e, principalmente, à ausência de um trabalho significativo de produção de textos na universidade.

PALAVRAS-CHAVE: Escrita acadêmica; Atitudes Ativas; Atitudes Táticas.

\section{1 lntrodução}

Não surpreende o número representativo de pesquisas sobre letramento em Linguística Aplicada (LA), porque, desde os momentos iniciais da constituição epistemológica dessa área, já é reconhecida a intrínseca relação das pesquisas desenvolvidas com o contexto social, com as práticas discursivas de usos da linguagem (MOITA LOPES, 
1996; 2006): foco de investigação que se correlaciona com os objetivos dos estudos do letramento. Porém, se antes a preocupação de LA era com a resolução de problemas sobre os usos da linguagem, na concepção de LA contemporânea, o propósito é problematizar ou criar inteligibilidades sobre esses usos, como é o caso das questões relacionadas com o letramento acadêmico.

No Brasil, o interesse pela escrita dos alunos de diferentes níveis de ensino não é recente, porém é um campo de estudos consolidado a partir dos anos oitenta e que começou a tomar uma expansão maior com as reflexões dos trabalhos desenvolvidos numa abordagem do letramento (FIAD, 2011). Sob essa perspectiva, os estudos que focalizam o letramento acadêmico indicam a necessidade de mudanças sobre o modo como se concebe a escrita dos alunos na universidade. Como afirma Zavala (2010, p.92), "em um sistema de ensino superior que busca ampliar o acesso e promover a diversidade, é necessário fazer do domínio educativo um espaço mais democrático."

Neste artigo, temos como objetivo compreender como alunos de Letras se constituem como produtores de textos escritos em português, visando a atitudes ativas (BAKHTIN, 1992, 1997) e táticas (DE CERTEAU, 2002, 2005). São análises realizadas em um projeto de pesquisa $^{1}$ concluído em 2007, no âmbito da Linguística Aplicada, cujos dados foram coletados num contexto de intervenção, em duas disciplinas ministradas pela mesma professora, no decorrer de dois anos letivos. Neste texto, retomamos a discussão estabelecendo um diálogo entre as reflexões de Bakhtin $(1992,1997)$ e De Certeau (2002, 2005) com os estudos sobre letramento.

\section{Um diálogo entre Bakhtin, De Certeau e} estudos do letramento acadêmico

0 diálogo entre as posições de Bakhtin $(1992,1997)$ e De Certeau (2002, 2005) com os estudos do letramento é bastante consensual em relação ao caráter ideológico e dialógico das práticas discursivas. Inclusive, essa iniciativa já foi realizada com a presença de Bakhtin nos estudos de Lillis (1999, 2003) e Fiad (2013).

A posição de Zavala (2010, p.73) sobre o modo como os estudos do letramento concebem a leitura e a escrita enquanto "sistemas simbólicos enraizados na prática social e inseparáveis de valores sociais e culturais" corresponde integralmente às concepções de Bakhtin 
$(1992,1997)$ e De Certeau (2002, 2005). De acordo com esses autores, é em cada relação interativa estabelecida nas práticas sociais, históricas e culturais que os sujeitos concretizam atitudes ativas e táticas.

A referência à compreensão ativa em Bakhtin $(1992,1997)$ vincula-se intrinsecamente a uma concepção dialógica de linguagem, que se caracteriza como um processo dialógico, criativo, intersubjetivo e ideológico. Mediante essa concepção, depreende-se um deslocamento significativo da concepção de sujeito. Bakhtin $(1992,1997)$ recusa a concepção de sujeito centrado na individualidade, fonte de criação, um "Adão bíblico" desvinculado das determinações sociais, como propunham os subjetivistas idealistas; também nega a concepção de um sujeito submetido às coerções e arbitrariedades de um sistema linguístico que o enreda no cerco da normatividade, conforme se configura no objetivismo abstrato.

As argumentações desse autor acerca de conceitos como dialogicidade, polifonia, polissemia, interação indicam uma visão de sujeito que se constitui nas relações intersubjetivas, submetido às determinações histórico-sociais, mas também tendo espaço para instaurar a dialogicidade do lugar de um interlocutor ativo que apresenta um embrião de resposta para expressar a compreensão sobre cada tema. À palavra do locutor é apresentada uma contrapalavra no processo de compreensão, por isso a significação não acontece em uma palavra isolada, senão "é o efeito da interação do locutor e do receptor, produzido através do material de um determinado complexo sonoro" e somente se realiza no processo de compreensão responsiva ativa, uma vez que "na realidade, não são palavras o que pronunciamos ou escutamos, mas verdades ou mentiras, coisas boas ou más, importantes ou triviais, agradáveis ou desagradáveis etc." (BAKHTIN, 1992, p. 132; 95).

As atitudes táticas, nas discussões de De Certeau (2002, 2005), também se efetivam na interação entre sujeitos (produtores e consumidores), nas diferentes esferas sociais, e correspondem às diversas possibilidades construídas pelo sujeito para criar espaços de criação e resistência frente às determinações estratégicas. Sob essa perspectiva, a linguagem é "um lugar organizado que permite atividades" (DE CERTEAU, 2005, p. 88). Assim, a linguagem não é um instrumento do qual o sujeito se apropria para estabelecer a comunicação, nem uma representação do pensamento e da realidade, mas é constitutiva dos sujeitos. Isso implica também considerar que a linguagem não tem 
um caráter estático e homogêneo, já que os sujeitos constroem e reconstroem essas atividades na dinamicidade e instabilidade das relações sócio-históricas.

Ao afirmar que as ações táticas são reprimidas por diferentes sistemas que adotam modelos estratégicos, De Certeau (2002) discute as implicações do sistema escriturístico, ou como ele denomina, da “economia escriturística:" um sistema que visa à disciplina, à reprodução, ao distanciamento da oralidade e, nas sociedades modernas ocidentais, expressa o progresso. Sob essa perspectiva, escrever é "uma atividade concreta que consiste, sobre um espaço próprio, a página, em construir um texto que tem poder sobre a exterioridade da qual foi previamente isolado" (DE CERTEAU, 2002, p. 225). Segundo esse autor, esse modo de conceber a escrita coloca o produtor de um texto numa posição de gerenciador de um espaço próprio, onde poderá executar um querer próprio. Assim, "as coisas que entram na página são sinais de uma "passividade" do sujeito em face de uma tradição; aquelas que saem dela são as marcas de seu poder de fabricar objeto.” (DE CERTEAU, 2002, p. 226).

Desse modo, a aprendizagem da escrita "define a iniciação por excelência em uma sociedade capitalista e conquistadora. É a sua prática iniciática fundamental." (DE CERTEAU, 2002, p.227). Esse poder consiste em um dos princípios de hierarquização social, podendo dominar, controlar, selecionar, de acordo com suas normas, todos aqueles que não possuem esse domínio da linguagem, como também garante a sua permanência através da produção da ideologia do consumo-receptáculo, cuja "eficácia da produção implica a inércia do consumo", diferenciando e privilegiando autores, pedagogos, revolucionários, tidos como produtores em relação àqueles que não o são (DE CERTEAU, 2002, p. 262). Segundo esse autor, a operação tática a ser executada nessa situação e, assim ter a chance de descobrir uma atividade criadora nesse campo do adversário, consiste em recusar o consumo, do modo como foi concebido por essas empresas de "auto-

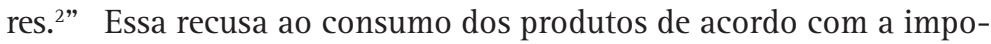
sição das empresas produtoras pode ocorrer em diversos acontecimentos que possibilitem o sujeito instaurar táticas, como nas práticas cotidianas (falar, ler, fazer compras, preparar refeições etc.) ou no trabalho com sucata. Para De Certeau (2005, p. 245), a criação pode acontecer em qualquer parte, sendo possível de ser concretizada em todas as espécies de linguagem. Há possibilidades de metaforizar, 
subverter de dentro do sistema a ordem dominante, fazendo-a funcionar em outro registro. Desse modo, o sujeito marca suas diferenças mesmo permanecendo no lugar organizado pelo sistema que o subjuga. Enfim, através do uso de táticas, ele consegue ser outro (diferente do que a ordem homogeneizante determina), mesmo estando no terreno do outro.

Essa relação intrínseca entre sujeitos, linguagem e realidade social evidenciada em Bakhtin (1992, 1997) e De Certeau (2002, 2005) é amplamente reiterada nos trabalhos que abordam letramento. Em se tratando de letramento acadêmico, diferentes autores são consensuais acerca do reconhecimento de que as dificuldades observadas na escrita de graduandos devem-se ao tratamento e às orientações adotados na universidade em relação à escrita de estudantes procedentes de diferentes classes sociais e etnias. De acordo com Fiad (2011, p. 362), nesse contexto "é requisitada aos alunos à escrita de gêneros sobre os quais eles não têm familiaridade nas experiências anteriores, não há uma correspondência entre os letramentos exigidos na universidade e os letramentos dos alunos". Zavala (2010, p.74) também expressa essa posição, argumentando que as dificuldades de interação entre estudantes e formadores sobre o letramento acadêmico "não se restringem simplesmente à técnica da escritura, às habilidades ou à gramática, mas a aspectos que estão relacionados com a identidade e a epistemologia."

A discussão apresentada por essas autoras dialoga com a reflexão de Lillis (1999), que caracteriza a prática de escrita acadêmica como prática institucional de mistério, que é ideologicamente fundamentada no sentido de não contribuir para que alguns grupos tenham familiaridade com as convenções da escrita acadêmica. Também se configura como uma prática dominante e complexa no contexto acadêmico. Essa autora ilustra e comenta, através de depoimentos de diferentes alunos, as implicações dessa prática do mistério para os alunos no cotidiano acadêmico.

0 conjunto das questões levantadas por esses pesquisadores indica as implicações geradas pela adaptação às novas formas de conhecimento no ensino superior, seja no plano da compreensão, interpretação ou organização do conhecimento (LEA; STREET, 1998). Nesse sentido, as dificuldades expressas pelos alunos, particularmente aqueles que integram as minorias, exigem, de acordo com Zavala (2010, p.93), a exploração de novas formas "pelas quais a escola possa validar o 
conhecimento das minorias, empoderá-las e educá-las para a transformação crítica da sociedade.” As experiências discutidas neste artigo foram movidas por esse desejo de alteração das práticas de escrita dos alunos, que se caracterizam como representantes dessas minorias.

\section{0 contexto da pesquisa e a caracterização do gênero resenha}

Os dados analisados foram gerados em uma pesquisa de cunho etnográfico com uma proposta de intervenção (ANDRÉ, 1995; TRIVIÑOS, 1997; ERICKSON, 1985), e adota as orientações teóricometodológicas desenvolvidas no âmbito da Linguística Aplicada. Como dissemos, a coleta de dados envolveu a participação dos mesmos alunos e da mesma professora em duas disciplinas distintas (Língua Portuguesa 1 e Língua Portuguesa 4) do Curso de Letras da Universidade Federal de Alagoas. Embora as disciplinas se configurassem com ementas e objetivos distintos, a professora direcionou todas as atividades de escrita previstas em cada disciplina sob uma perspectiva de reflexão dos alunos acerca de sua escrita.

A análise proposta neste artigo contempla dados de entrevistas, realizadas com os alunos, e de resenhas produzidas sobre livros e artigos lidos e discutidos, no decorrer das disciplinas, acerca de diferentes temas, muitos dos quais indicados pelos alunos nos questionários de caracterização aplicados no início de cada disciplina, sobretudo na disciplina do primeiro ano, cuja ementa possibilitava uma maior abertura. Como se tratava de uma investigação que priorizava a análise processual da escrita dos alunos, todos os textos foram reescritos e, nas orientações das condições de produção discutidas entre professora e alunos, era previsto que a professora e a turma seriam os interlocutores de cada texto. Assim, os sujeitos da pesquisa - Bianca, Gabriel, Heloísa e Helena ${ }^{3}$ - concordaram que seus textos pudessem ser objeto de análise durante as aulas das disciplinas e em situações de pesquisa. Desse modo, foi constituído um corpus com 36 textos, a maioria refere-se a resenhas: gênero priorizado no trabalho das duas disciplinas, além de entrevistas e questionários. A prioridade dada a esse gênero para se trabalhar nos dois anos letivos se justifica tanto por ser um dos temas da disciplina Língua Portuguesa 1 (doravante LP) quanto por haver a necessidade de os alunos terem domínio da escrita desse gênero para elaborar o Trabalho de Conclusão de Curso, 
realizado no quarto ano. Portanto, a constituição de resenhas nos dois anos letivos daria subsídios aos alunos para a escrita do trabalho final, consistindo em uma tentativa para ajudá-los a descobrir e compreender os mistérios (LILLIS, 1999) em relação à escrita desse gênero acadêmico.

Com base nas ideias de Bakhtin (1997, p. 281), concebemos a resenha acadêmica como um gênero secundário e, como tal, corresponde a circunstâncias de "uma comunicação cultural mais complexa e relativamente mais evoluída, principalmente escrita: artística, científica, sociopolítica." Portanto, é um gênero que é elaborado e utilizado em circunstâncias que se distanciam das relações cotidianas, e tem uma padronização formal. Ao contrário de outros gêneros, como por exemplo, o relato de viagem e o bilhete, na resenha há maiores determinações que cerceiam a liberdade e a criatividade. De um modo geral, autores que discutem a construção do gênero resenha, como Bezerra (2002), indicam como unidades de organização de uma resenha acadêmica: introdução, resumo e crítica da obra comentada.

Bakhtin (1997) nos alerta para o fato de que todos os gêneros têm um certo grau de estabilidade ou normatividade, embora sejam formas passíveis às mudanças histórico-sociais. Ainda segundo esse autor, em todos os gêneros há algum tipo de relação dialógica. Portanto, mesmo em uma resenha acadêmica, existe possibilidade de expressão ativa e tática. Essa é uma questão que observaremos na análise da escrita dos alunos.

\section{Um olhar dialógico sobre a escrita dos alunos}

Todo o trabalho realizado nas disciplinas foi embasado numa concepção dialógica de linguagem. Por isso, mesmo com os cerceamentos da escrita no contexto acadêmico, devido, sobretudo às exigências dos gêneros que deveriam ser priorizados em cada disciplina, as aulas caracterizavam-se como espaços nos quais aconteciam amplos e longos diálogos entre professora e alunos sobre seus textos. Para caracterizar o processo de escrita dos alunos desde os momentos iniciais na universidade, analisamos produções de textos realizadas no decorrer de cada ano letivo, nas duas disciplinas. Porém aqui mencionaremos apenas trechos ilustrativos de resenhas produzidas, entremeando a análise com vozes dos alunos expressas nos momentos em entrevistas. 
Entre as questões observadas nas produções tanto do primeiro quanto do quarto ano, o aspecto mais evidente é a dificuldade de eles se desvincularem da concepção de escrita como modelo preestabelecido e compreenderem a escrita como prática discursiva, social e situada. Essa questão é compreensível (e até previsível), quando levarmos em consideração, entre outros aspectos, as histórias de escrita dos alunos anteriores à universidade, o desconhecimento deles sobre as exigências de escrita dos gêneros acadêmicos, as práticas de mistério sobre essa escrita, como discute Lillis (1999).

$\mathrm{Na}$ análise processual sobre as resenhas produzidas no primeiro ano, observamos que as vozes arraigadas sobre a escrita como modelo são reiteradas nas resenhas produzidas pelos alunos. As conclusões da segunda versão das resenhas elaboradas por Bianca ilustram esse aprisionamento à prática monológica e estratégica de escrita:

\begin{tabular}{|l|l|}
\hline $\begin{array}{l}\text { Resenha sobre os tex- } \\
\text { tos de Frei Beto e Má- } \\
\text { rio Prata }\end{array}$ & $\begin{array}{l}\text { Analisando as ideias discutidas pelos dois } \\
\text { autores, podemos fazer um questionamento } \\
\text { a respeito do valor de nossa participação } \\
\text { no quadro político-social do Brasil. }\end{array}$ \\
\hline $\begin{array}{l}\text { Resenha sobre o livro } \\
\text { São Bernardo }\end{array}$ & $\begin{array}{l}\text { Analisando a obra citada, percebemos que } \\
\text { o seu caráter político é expresso em todo o } \\
\text { enredo. Graciliano Ramos consegue desper- } \\
\text { tar o leitor para um posicionamento crítico } \\
\text { a respeito dos bens gerados pelo capitalis- } \\
\text { mo e pelo socialismo. }\end{array}$ \\
\hline $\begin{array}{l}\text { Resenha sobre o livro } \\
\text { de Zamoner }\end{array}$ & $\begin{array}{l}\text { Airo Zamoner abordou as questões políti- } \\
\text { cas de forma coerente, fazendo uso de um } \\
\text { vocabulário facilmente compreendido pelo } \\
\text { leitor e nos conduzindo a um } \\
\text { posicionamento crítico a respeito da parti- } \\
\text { cipação da sociedade no quadro político e } \\
\text { social da nação. }\end{array}$ \\
\hline
\end{tabular}

Observemos, no quadro acima, que na apreciação crítica, que em geral acontece na conclusão, Bianca reproduz um modelo preestabelecido que se constitui de uma afirmação genérica com uma 
proposta clichê, convocando o interlocutor para um questionamento/ posicionamento crítico em relação ao quadro político-social do Brasil/nação. Embora ela demonstre uma compreensão sobre a organização composicional do gênero resenha e expresse reflexões críticas durante as aulas, enreda-se nos cercos de reprodução escriturística (DE CERTEAU, 2002), juntamente com Gabriel e Heloísa, que também constroem uma conclusão com grandes semelhanças:

Após a leitura deste livro, pode-se concluir que o autor através de uma linguagem leve e bastante satírica. Leva-nos a refletir sobre o real desempenho de nossos políticos e da influência da mídia em nossas vidas. (Gabriel)

O livro "As Companhias do Presidente", trata de temas políticos, sociais, econômicos etc., de uma forma leve mas eficiente, narrando histórias cômicas, que nos trazem a nossa realidade. (Heloísa)

No parágrafo conclusivo das três resenhas sobre o livro As companhias do presidente, de Airo Zamoner, há referência à leveza no tratamento dos temas como consequência da linguagem utilizada pelo autor, também existe uma convocação para que se faça uma reflexão sobre problemas da realidade brasileira. É interessante notar que os três alunos sugerem essa reflexão usando a primeira pessoa do plural, como se observa nos discursos de militância política: "nos conduzindo a um posicionamento crítico;" "leva-nos a refletir;" "nos trazem a nossa realidade."

É possível justificar essa recorrência ao modelo utilizada por Bianca, Gabriel e Heloísa se considerarmos a possibilidade de a conclusão de um dos primeiros textos ter recebido elogios da professora num momento de discussão dos textos durante uma aula. Nesse caso, ao compreender que se tratava de uma forma de dizer que havia sido legitimada, principalmente pela voz de poder da professora, os alunos começaram a adotar essa forma de dizer como modelo, movidos, talvez, pela crença de que era a forma "certa". Fiad (1993 e 1997) também constatou semelhanças entre textos de alunos universitários, compreendendo-as como evidências de homogeneização da escrita. Sobre esse caráter homogeneizante na escrita de alunos, Medeiros (1991, p. 115), em uma análise sobre a produção de textos no ensino fundamental, conclui que, nos primeiros anos, os textos se diferenci- 
am dos modelos, porém, nos anos seguintes, os textos são cada vez mais semelhantes uns aos outros e começam a aparecer fórmulas e frases feitas.

No contexto acadêmico, a desconstrução e/ou mudança dessa concepção de escrita como prática monológica, homogeneizante, constitui um dos maiores desafios dos professores que defendem e desenvolvem um trabalho de escrita fundamentado numa perspectiva dialógica, tática, situada, desveladora de mistérios, como propõem Bakhtin (1992,1997), De Certeau (2002, 2005) e Lillis (1999), porque, além de a escrita ser majoritariamente concebida ainda como habilidade na universidade, as experiências anteriores de escrita dos alunos são calcadas, em geral, nessa mesma perspectiva. Sob tal perspectiva, Zavala (2010, p.90) afirma que, na universidade, os professores "normalmente caracterizam seus estudantes baseados em discursos do déficit e concebem o letramento acadêmico como algo que cumpre um papel remedial no ensino superior." Somado a isso, as práticas de escritas ainda ocupam espaços bastante restritos nesses dois contextos de ensino, como afirma Heloísa: "em minha vida escolar, no fundamental, mal tive produção textual, e o ensino médio, como eu fiz um curso técnico, também tinha poucas produções textuais, não trabalhei muito não com isso." Na declaração de Bianca, ela enfatiza a ausência de experiências de escrita nas disciplinas LP 2 e 3 durante seu período de graduação:

No primeiro ano, no primeiro e no quarto ano, no primeiro e no quarto ano, a produção era trabalhada assim: a gente tinha, primeiro antes de produzir, a gente discutia muito sobre o assunto na sala. Debatia, a professora trazia vários textos pra gente ler a respeito daquele assunto, a gente nunca ia inocente pra um tema, então discutia bastante, debatia e depois a gente ia escrever e aí começava escrever, reescrever, reescrever e era assim até o texto ficar bom. No segundo ano, a gente praticamente não trabalhou produção e nem trabalhou gramática, não sei o que a gente fez no segundo ano ((risos)). No segundo ano, a única coisa que a gente fez foi tirar xerox. 0 terceiro ano se voltou mais assim à questão da interpretação e do entendimento de períodos e orações, praticamente foi isso o ano inteiro: a gente pegando trechos de algum texto e tentando entender como era que ele tinha sido construído: a coesão entre períodos, entre orações, entre palavras. Então foi praticamente isso, a gente não produziu texto no terceiro ano não, produziu apenas no primeiro e no quarto. 
Nessa declaração, compreendemos que Bianca se refere à ausência de produção de textos em dois anos letivos porque associa produção de textos à caracterização do trabalho realizado nas disciplinas LP 1 e 4, ou seja, um trabalho com práticas discursivas de escrita. Provavelmente, foram produzidos textos em LP 2 e 3 e em outras disciplinas, porém foram realizadas em provas, análises de textos ou em outros trabalhos acadêmicos, sob uma perspectiva meramente descritiva. 0 modo como ela se refere à reescrita de textos sugere tanto contínuas reflexões sobre o mesmo texto quanto repetições. Assim, é possível que as reproduções que ela apresentou como proposta para a conclusão das resenhas se justifiquem pela incompreensão sobre a conceito de escrita como prática discursiva, como propunham as orientações adotadas pela professora que, em meio às determinações do cotidiano, não observou as repetições nem as semelhanças entre os textos durante o desenvolvimento da disciplina. Isso somente aconteceu depois que os textos transformaram-se em objeto de pesquisa. Considerando as reflexões de Erickson (2001), compreendemos a falta de percepção da professora sobre esses aspectos como "pontos cegos" que o envolvimento na condução das atividades pedagógicas às vezes ofusca e somente a pesquisa contribui para desvelá-los.

Se, por um lado, houve homogeneização em alguns momentos na escrita dos alunos que indicam um aprisionamento às determinações da "economia escriturística" (DE CERTEAU, 2002) imposta pelos produtores; por outro, também aconteceram episódios em que os alunos conseguiram extrapolar o cerco das determinações e imprimiram marcas de responsividade e tática em seu dizer, como ilustram os seguintes trechos de uma resenha de Helena:

Airo Zamoner em seu livro As Companhias do Presidente, utilizase de uma linguagem de fácil assimilação para satirizar o comportamento dos governantes e do povo de um determinado país.

0 livro é formado por três contos que tratam sobretudo do poder constituído e das atitudes do povo diante da realidade em que vivem $[. .$.

A intenção do autor de colocar o tema do segundo conto de "0 governador de Muletas," foi uma forma para analisarmos como o sistema em que estamos inseridos tem um propósito capaz de alienar, de manipular, seja nas religiões, na política ou em qualquer relação 
de poder, pois existe porque há quem o sustente. A palavra "muletas" também pode referir-se ao consumo, à moda, ou seja, algumas pessoas consomem o que é fabricado fora de seu país, pagam mais caro, desvalorizam o produto interno e ainda fazem propaganda para as grifes de luxo. Este comportamento ocorre porque elas não refletem e são assediadas pelas propagandas e pela moda. [...]

Diante das questões e com base na leitura, podemos observar que o propósito do autor em relação ao comportamento de um povo é que enquanto este se acomoda não há mudança. Quando ele afirma: "0 povo não sustentou mais o palácio", significa dizer que o povo despertou em relação à realidade em que vivia tomando uma iniciativa no sentido de transformar o quadro político tornando o poder enfraquecido.

Ao contrário do que acontece, em geral, nas resenhas escritas por produtores alunos recém-ingressantes na universidade, Helena não expressa sua posição acerca do livro resenhado apenas no final do texto, mas se posiciona à medida que apresenta as ideias. Além disso, ela demonstra compreender a escrita como prática discursiva quando, provavelmente, deslocando-se para o lugar dos leitores de seu texto, vislumbra um possível diálogo estabelecido acerca dos possíveis sentidos da palavra muleta no texto ("A palavra 'muletas' também pode referir-se ao consumo, à moda, ou seja, algumas pessoas consomem o que é fabricado fora do país fora de seu país, pagam mais caro, desvalorizam o produto interno e ainda fazem propaganda para as grifes de luxo."). Essa proposta de diálogo com seu interlocutor também é demonstrada na conclusão da resenha, quando ela convoca o autor do texto resenhado e imprime sua compreensão sobre as ideias do texto.

Mesmo ainda inseguros quanto às suas práticas de escrita, sobretudo pelas exigências da universidade, os alunos concluem o primeiro ano reconhecendo a importância de refletirem sobre seu processo de escrita, como declara Bianca na avaliação de seu desempenho na disciplina: "Em relação aos trabalhos anteriores, me envergonho sempre que releio, não que os últimos estejam ótimos, mas melhoraram um pouquinho". Esse caráter reflexivo e comparativo também é apresentado nas discussões de Fiad (2011). Vemos essa compreensão sobre a necessidade de o aluno rever seu processo de escrita, assim como o espaço apresentado pela professora para dar voz aos alunos como indícios de uma mudança que precisa acontecer nas 
práticas de escrita do contexto acadêmico. Entretanto, há focos de resistência na universidade que obstruem essa possível mudança, como afirma Bianca na reflexão que apresenta no início das atividades do quarto ano. Ao falar sobre retomada da proposta de escrita iniciada no primeiro ano e das experiências vivenciadas no segundo e terceiro ano, ela declara:

... agora no quarto ano não consigo mais produzir nada ... pra mim tá o maior sufoco sentar pra pensar, escrever a respeito. Eu sei, eu tenho as ideias na cabeça, mas eu não consigo mais passar pro papel. Eu argumento, eu sei do que se trata, eu comparo e tudo, mas a questão da escrita pra mim ta difícil, não consigo mais escrever. É que a gente começou num ritmo do primeiro ano e cortou, praticamente a gente não teve mais isso, aí quando chega no quarto agente tem que produzir novamente.

Essa posição de Bianca assemelha-se, de algum modo, às declarações dos alunos apresentadas em Lillis (1999) e Zavala (2010) e justifica algumas dificuldades expressas pelos alunos no quarto ano. Eles chegaram a esse momento do curso com ideias e posições talvez mais arraigadas sobre a escrita monológica do que no primeiro ano. Possivelmente, esse é um reflexo das orientações adotadas nos dois anos anteriores que, como afirma Bianca, resumiram-se, basicamente, à cópia e a exercícios de identificação e classificação: "No segundo ano, a única coisa que a gente fez foi tirar xerox. 0 terceiro ano se voltou mais assim à questão da interpretação e do entendimento de períodos e orações, praticamente foi isso o ano inteiro do entendimento de períodos e orações."

Entre as diferentes as dificuldades observadas na escrita dos alunos no quarto ano, selecionamos como ilustração um fato apresentado em uma das resenhas escritas por Helena, que finalizou o primeiro ano como uma das alunas mais reflexivas da turma. Numa das resenhas do quarto ano sobre o texto Os primeiros sinais, de Bernadete Abaurre, ela silencia a autora e faz uma paráfrase muito colada ao texto:

Reflexões sobre estilo de há muito ocupam os teóricos da literatura e alguns linguistas interessados em uma melhor compreensão dos usos e do funcionamento da linguagem. Teorias sobre estilística baseiam-se, no entanto, em dados representativos da linguagem adulta, quer em suas manifestações escritas, quer em suas manifestações orais. (Abaurre) 
As reflexões sobre estilo não são recentes. Há décadas, teóricos, literários e linguistas se preocupam em buscar uma melhor compreensão sobre os usos e funcionamentos da linguagem. Todavia, as teorias vistas até então baseiam-se em dados da linguagem adulta, seja em suas manifestações, orais e/ou escritas. (Helena)

Essa apropriação inadequada das ideias do texto comentado é a primeira vez que acontece com Helena e, surpreendentemente, na última produção do quarto ano, após ter vivenciado diferentes experiências com atividades de produção. Ela apropria-se das ideias da autora no decorrer de toda a resenha, por isso os comentários da professora, antes da segunda versão, foram com questionamentos para que ela refletisse sobre essa questão. Na segunda versão, Helena responde aos questionamentos da professora sobre a autoria das ideias da introdução, mencionando o nome de Abaurre, ficando assim o primeiro parágrafo:

Maria Bernadete Abaurre (1997) coloca que as reflexões sobre estilo há muito ocupam teóricos literários e linguistas interessados em uma melhor compreensão sobre os usos e funcionamentos da linguagem. Todavia, ela chama a atenção para esses estudos que são baseados, apenas, em dados da linguagem adulta. Diante disso, a estudiosa inaugura, em seus estudos sobre aquisição da representação escrita da linguagem, uma pesquisa em que observa a diferenciação estilística presente nas produções textuais de M.L., uma aluna de $1^{\mathrm{a}}$ série.

De acordo com esse parágrafo introdutório, juntamente com a referência bibliográfica citada acima desse parágrafo, o interlocutor compreende que se trata de uma resenha sobre o texto de Abaurre. Entretanto, a partir do segundo parágrafo essa expectativa é frustrada, porque Helena começa a fazer análises de textos mencionados por essa autora, repetindo-se, assim, o mesmo procedimento que ela adotou na versão anterior. É muito provável que isso aconteça porque ela não sabe como comentar textos que contenham análise. Supomos que ela reescreveu o texto de forma semelhante à versão anterior não por incompreensão da proposta da atividade ou das intervenções da professora. Caso contrário, ela teria reescrito o parágrafo da introdução também de modo semelhante à versão anterior. Um dado na conclusão nos indica que a dificuldade de Helena pode mesmo ter como uma possível explicação o fato de o texto resenhado ser constituído predominantemente de análises de dados. Comentar textos com essa 
caracterização, indicando a autoria da análise, ainda consiste em um "mistério" (LILLIS, 1999) para Helena. Assim, ela consegue introduzir a conclusão mencionando que o texto sobre o qual está comentando é de Abaurre, mas imediatamente, ao falar dos dados, ela assume a autoria da análise, como vemos em :

Embora não tenha observado comentários de Abaurre sobre o papel de M.L. em sala de aula, seja na relação com uma heterogeneidade de gêneros textuais, seja diante de condições de produção oferecidas, podemos concluir que a história de vida da aluna pode ter influenciado de forma definitiva no seu processo de aquisição da linguagem. Obviamente, se o sujeito se relaciona bem com todos os gêneros discursivos isso quer dizer que no momento de escrita ele procura refletir sobre o processo e produz em seu texto o efeito de sentido que deseja. Certamente, é nessa realidade que pensamos estar a aluna em questão.

Nesse parágrafo conclusivo, Helena inicia convocando a autora antes de expor os resultados da análise e tenta fazer considerações sobre as ideias desenvolvidas pela autora do texto comentado, porém, logo em seguida, retira a autora do foco e comenta os resultados da análise dos dados como se a análise não fosse uma proposta de Abaurre. Levando-se em consideração todo o processo de escrita de Helena, sobretudo como ela finalizou o primeiro ano, essas dificuldades também podem estar associadas, além das especificidades dos textos resenhados, à ausência de reflexão sobre a sua produção. É possível que, devido ao acúmulo de atividades do quarto ano e às atividades profissionais, ela não relesse criteriosamente seus textos depois de produzi-los, mantendo um distanciamento necessário para perceber nuances como essa de apropriação das ideias da autora e, de fato, expressar atitudes ativas e táticas.

\section{Algumas considerações finais}

0 diálogo construído com os alunos sobre o seu processo de escrita, desde os momentos iniciais de envolvimento com o letramento acadêmico, é meio tenso quando observamos que a concepção de escrita dominante no meio acadêmico desencadeia sérias implicações na formação dos alunos. Enredados nas construções e exigências estratégicas do sistema escriturístico (DE CERTEAU, 2002, 2005), os alunos iniciam e concluem o curso com exíguos espaços para expressar atitudes responsivas e táticas. Mesmo quando eles desvelam al- 
guns aspectos da prática de mistérios (LILLIS, 1999) e conseguem apropriar-se das convenções da escrita acadêmica, ainda há evidências de vácuos, instâncias nebulosas e inquietantes, como sugere a declaração de Bianca sobre suas experiências de escrita no início do quarto ano: "Eu sei, eu tenho as ideias na cabeça, mas eu não consigo mais passar pro papel. Eu argumento, eu sei do que se trata, eu comparo e tudo, mas a questão da escrita pra mim ta difícil, não consigo mais escrever."

A possibilidade de estabelecer essa interação com os alunos, a instauração desse espaço dialógico, numa tentativa de compreender os desejos, as dificuldades, as frustrações dos alunos são iniciativas importantes porque a ausência de interação com os professores consiste em uma das maiores dificuldades na trajetória dos alunos no contexto acadêmico.

Nesse contexto, os poucos momentos em que os alunos tentam se desvincular do modelo e dão sinais de reflexão sobre o seu dizer, expressando uma atitude ativa e tática são significativos, principalmente no primeiro ano, quando se deparam com um mundo cultural totalmente diferente do que vivenciaram até então. Por isso os poucos indícios de responsividade e tática são previsíveis se considerarmos que eles estavam vivenciando pela primeira vez experiências como: a reescrita de textos sob uma perspectiva dialógica, a prática de discussão de seus textos por toda a turma, a possibilidade de uma reflexão sobre suas ideias numa visão de processo, a instauração de diálogos com a professora sobre seu dizer, enfim, uma série de aspectos completamente novos para eles.

Diante dessa realidade, provavelmente os alunos apresentariam maior incidência de atitudes ativas e táticas se as intervenções da professora tivessem acontecido com orientações individuais. Isso é totalmente impraticável em turmas com um grande número de alunos, como a do primeiro ano dos alunos em foco. Acreditamos que, mesmo com comentários mais específicos em seus textos, os alunos necessitariam de um acompanhamento mais próximo para transpor as barreiras na sua constituição como produtores. Muitos apagamentos realizados pelos alunos na segunda versão foram decorrentes de diálogos inconclusos entre professora e alunos. 0 diálogo não se efetivava, porque eles não sabiam que alternativa propor para o questionamento da professora, então apagavam os trechos com esses questionamentos. Helena, ao ser questionada sobre os apagamentos 
de seu texto, declara: "Acho que no meu caso é dificuldade mesmo de colocar na escrita o que eu pensava. Eu sinto dificuldade." E acrescenta: "O aluno tem o posicionamento crítico, mas não sabe colocar, a maneira de dizer é muito grotesca."

Vale mencionar a relação dialógica entre professora e alunos que subsidiou o trabalho realizado nas duas experiências. Esse diálogo se efetivou de diferentes modos, como na solicitação aos alunos de sugestões de temas para as produções com os quais eles se identificavam, nas diferentes discussões realizadas antes da escrita, na ideia de processo que subsidiou todo o trabalho, estabelecendo um diálogo entre as vivências dos dois anos letivos. Evidentemente, são relações dialógicas ainda presas a uma série de coerções, por essa razão, algumas vozes que perpassaram a história da professora e dos alunos, como também os cerceamentos da cultura acadêmica, inviabilizaram uma maior abertura para a realização de operações de caça que dessem mais espaço às atividades criadoras (DE CERTEAU, 2002, p. 262).

Comungamos com a posição dos pesquisadores do letramento acadêmico, aqui mencionados, de que é preciso alterar a realidade do letramento dos alunos. Se esses alunos chegam à universidade e não saem dessa instituição, efetivamente, escrevendo com reflexão, com domínio dos mecanismos de escrita que lhes possibilite construir inúmeras atitudes ativas e táticas, acreditamos que a primeira iniciativa para reverter essa situação é enfrentá-la como real e, a partir daí professores e alunos precisarão discutir até onde implica o poder de interferência de cada um para mudar essa realidade. E, mediante as alternativas indicadas nessas discussões, necessitarão buscar formas de efetivá-las, reconhecendo as determinações impostas ao ensino pelas práticas institucionais. 
ABSTRACT

This article is a result of an ethnographic-based research carried out in the Applied Linguistics area in order to understand the constitution of Languages Graduate Course undergraduate students as producers of Portuguese-written texts, with a focus on active and tactical attitude. The corpus consists of students' interviews and writing and rewriting texts activities, which were held throughout two disciplines of the course, taught by the same teacher. Data analysis highlights few times when students performed active and tactical attitude in the writing process activities in both disciplines. This result is among other reasons due to the history of each student as a producer of texts in basic education, and above all the absence of a significant work in producing texts in the Languages Graduate Course. KEYWORDS: Academic Writing; Active Attitude; Tactical Attitude.

\section{REFERÊNCIAS}

ANDRÉ, Marli. Etnografia da prática escolar. Campinas: Papirus, 1995.

BAKHTIN, Mikhail. Marxismo e filosofia da linguagem. 6. ed. Traduzido por Michel Lahud e Yara F. Vieira. São Paulo: Hucitec, 1992.

Estética da criação verbal. 2. ed.Traduzido por Maria Ermantina G.

G. Pereira. São Paulo: Martins Fontes, 1997.

BEZERRA, Benedito Gomes. A organização retórica de resenhas acadêmicas. In: Linguagem em (Dis)curso, v.3, n.1, p. 37-68, jul.-dez., 2002.

DE CERTEAU, Michel. A invenção do cotidiano: artes de fazer. 7. ed. Traduzido por Ephraim Ferreira Alves. Petrópolis: Vozes, 2002.

- A cultura no plural. 4. ed. Traduzido por Enid Abreu Dobránszky.

Campinas: Papirus, 2005.

ANDRÉ, Marli. Etnografia da prática escolar. Campinas: Papirus, 1995.

ERICKSON, Frederick. Prefácio. In: COX, Maria Inês P. ct ASSIS-PETERSON (Org.). Cenas de sala de aula. São Paulo: Mercado de Letras, 2001, p. 9-17. FIAD, Raquel. Reescrita, dialogismo e etnografia. In: Linguagem em (Dis)curso (Impresso), v. 13, p. 463-480, 2013. 
A escrita na universidade. Revista da ABRALIN, v. Eletrônico, n. Especial, p. 357-369. 2. parte, 2011.

0 estilo escolar. In: Cenas de aquisição da escrita: o sujeito e o trabalho com o texto. Campinas: ALB: Mercado de Letras, 1997, p. 195-204.

. Estilo e homogeneidade: análise de textos de universitários. In:

Estudos Linguísticos XXII, Ribeirão Preto, v.1, p. 180-7, 1993.

LEA, M.R.; STREET, Brian. Student writing in higher education: an academic literacies approach. Studies in Higher Education. London. June, v. 23, n. 2, p. 157-16, 1998.

LILLIS, Theresa. Whose 'Common Sense'? Essayist literacy and the institutional practice of mystery. In: JONES, C.; TURNER, J.; STREET, B. (Orgs.). Students writing in the university: cultural and epistemological issues. Amsterdam. John Benjamins, 1999. p. 127-140.

Student writing as 'academic literacies': drawing on Bakhtin to move from critique to design. In: Language and education, v. 3, n. 17, p. 192-207, 2003.

MEDEIROS, Beatriz Raposo de. Redação: um caso sério. Dissertação de Mestrado. Campinas, UNICAMP, 1991.

MOITA LOPES, L. P. Oficina de lingüística aplicada: a natureza social e educacional dos processos de ensino/aprendizagem de línguas. São Paulo: Mercado de Letras, 1996.

Por uma Lingüística Aplicada Indisciplinar. São Paulo: Parábola, 2006.

SANTOS, L. F. Produção de textos na universidade: em busca de atitudes ativas e táticas. 2007. 250 f. (Doutorado em Linguística) Universidade Federal de Alagoas, Maceió.

TRIVIÑOS, Augusto. Introdução à pesquisa em Ciências Sociais: a pesquisa qualitativa em educação. São Paulo: Atlas, 1987.

ZAVALA, Virgínia. Quem está dizendo isso? Letramento acadêmico, identidade e poder na educação superior. In VÓVIO, Cláudia; LUANDA, Sito; DE GRANDE, Paula (org.). Letramentos. São Paulo: Mercado de Letras, 2010.

NOTAS

${ }^{1}$ Trata-se de dados inéditos da pesquisa de doutorado de Santos (2007), cuja coleta foi realizada nos anos de 1998 e 2001.

${ }^{2} 0$ uso das aspas na palavra autores marca uma posição irônica de De 
Certeau. Conforme ele defende em outros momentos, o autor, de fato, subverte as leis do sistema no qual se insere, pratica os procedimentos do desvio de dentro desse sistema. Ilustra a posição de autor o seguinte exemplo, apresentado por ele (2002, p. 94): uma criança que rabisca e suja o livro escolar, mesmo que receba um castigo por esse crime, ganha um espaço, assina aí a sua existência de autor.

${ }^{3}$ Usamos nomes fictícios para preservar a identidade de cada sujeito.

Recebido em 29 de maio de 2015

Aprovado em 05 de junho de 2015 